\title{
Misconduct in medical research: Does it exist in Britain?
}

\author{
Stephen Lock
}

\section{Introduction}

All studies of deviance are plagued by the difficulty of estimating prevalence; accusers use the numerator and defenders the denominator. ${ }^{1}$ In thinking about the problems in Britain earlier this year I could remember only five cases of medical misconduct (a blanket term to cover plagiarism and misrepresentation as well as outright fraud) (box). Nevertheless, a friendly radiologist told me about a much earlier case - which if not the first proved case in British medicine certainly seems likely to have provoked the first formal retraction in a medical journal.

In 1916 the $B M F$ published an article about the work done by James Shearer, an American physician working in the British Army as a sergeant (because he had no British qualification). He had described a "delineator" which was better than $x$ rays for portraying gunshot wounds (fig 1 (top), fig 2).? This caused a sensation and a lot of interest - but on investigation the work was found to have been invented. The $B M F$ published a retraction (fig 1 (bottom)), ${ }^{8}$ but Shearer was tried by court martial and sentenced to death by firing squad. ${ }^{9}$ Fortunately, the sentence was commuted to penal servitude, but Shearer died only a year later in prison. Unfortunately, the details are held in secret files until 2017, but the story brings a macabre twist to the well known New Yorker cartoon (fig 3).

Six cases in medicine over, say, 70 years do not seem very many-in fact this is much closer to Koshland's estimate of purity of $\mathbf{9 9 . 9 9 9 9 \%}$ of pieces of scientific information ${ }^{10}$ than to the estimate by Broad and Wade of very many concealed frauds for every major case in

THE DELINEATION OF INTERNAL ORGANS BY AN ELECTRICAL METHOD

THE manner in which the application of scientific methods to the medical work of the British Expeditionary Force in France is encou:aged and the results obtained have been the subject of remark in various places, and several advances in medicine and surgery have already been recorded in these columns.

No public statement, however, has anywhere yet been made regarding a piece of work of an unusual and somewhat puzzling cor puzaling chareter, which has been in progress at one of the surmises, and conflicting views.

The first subject that it brings in to mind is $x$-ray photography and the next is wireless teler surmises, and

of when the Finance but tu wis year is being alscussed in the House of Commons.

THE DELINEATION OF INTERNAL ORGANS

In an article entitled "The delineation of internal organs by an electrical method," published in this JOURNAL in September last, an account was given of a device which at about that time was attracting some attention in the British Expeditionary Force. Information subsequently received seemed to justify us three weeks later in expressing the anticipation that we should be able to publish a full account of the method and results in an early issue. This expectation has not been fulfilled, and we have reason to believe that the inventor has failed to satisfy the physicists consulted as to the truth of his claims.

\section{Brish Medical Journat}

Stephen Lock, MD, editor

Based on an address to a conference on ethics and policy in scientific research held by the Council of Biolog Editors, National Academy of Sciences, Washington DC, 16-18 October 1988. by an electrical method in "BMF," 30 September 1916; bottom retraction of article in "BMF," 24 March 1917

\begin{tabular}{|c|c|c|}
\hline \multicolumn{3}{|c|}{ Documented British cases of misconduct } \\
\hline Alsabti & 1970s & $\begin{array}{l}\text { Plagiarism of various } \\
\text { (60) articles }\end{array}$ \\
\hline Purves & 1981 & $\begin{array}{l}\text { Invention of data on } \\
\text { fetal glucose } \\
\text { metabolism }\end{array}$ \\
\hline Connolly & 1986 & $\begin{array}{l}\text { Plagiarism of } B M \mathcal{F} \\
\text { editorial }^{4}\end{array}$ \\
\hline "Canteloupe" & $1950 \mathrm{~s}$ & Piracy of ideas ${ }^{5}$ \\
\hline Siddiqui & 1988 & $\begin{array}{l}\text { Invention of data on } \\
\text { drug trial }^{6}\end{array}$ \\
\hline
\end{tabular}

science that becomes public." Perhaps there were reasons why the pattern was different in Britain from that in the United States. In casual conversation British doctors would cite the hectic research pace in the States, with its emphasis on positive results, hinting that the more civilised, relaxed demands in Britain make malpractice less likely. Even so, I was struck when I talked, say, at postgraduate centres about misconduct in medical research how doctors would sidle up to me after the lecture and tell me about an unpublicised instance, sometimes but not always in some detail. Physicians concerned with or in drug companies seemed to be particularly cynical. And then I thought of the masterly survey by Pat Woolf, whose paper last year made me conclude that present day knowledge in Britain resembled that in the United States less than a decade ago. ${ }^{1}$ In 1980 in the United States only four cases of misconduct had been recognised, and then a series of reports had hit the headlines, followed by books and congressional inquiries on the subject. After doing a survey of some of the main research bodies Woolf concluded that there was no evidence of an epidemic of fraudulent science in the United States but that there was a persistent and growing concern about the conduct of science and its publication.

In Britain any study of misconduct is more difficult than in the United States. In particular, we have no Freedom of Information Act and very stringent laws of libel; the smallness of the country means that any accusation is likely to be heard in every medical school, with serious implications. On the other hand, this smallness does mean a closely knit medical society whose members can be asked in strict confidence for their experience of misconduct. Hence I used this positive feature to do a non-systematic survey.

\section{Methods}

I wrote to one professor of medicine and one of surgery in each of 29 medical institutions in Britain asking whether they could add any cases of fraud to those already documented in Britain; a second question was about any mechanisms in their medical school for dealing with future cases. I also wrote to anybody whom these respondents suggested might help; a total of five other academics and other doctors whom I knew had experience or a special interest in the topic; two scientists concerned with managing medical research; and editors of 15 medical journals. Each letter was accompanied by a duplicate on which the respondent could reply, a stamped addressed envelope, and a copy of an editorial ${ }^{12}$ that I had written

FIG 1-Top: article on 7 ames Shearer describing delineation of organ 


\section{Reported medical misconduct in Australia}

$\begin{array}{ll}\text { Name } & \text { Discipline } \\ \text { Michael Briggs } & \text { Endocrinology } \\ (1981-7) & \text { (Deakin Univers }\end{array}$

(1981-7)

(Deakin University)

Ronald Wild

(1985)

Professor and dean of social science (La

Trobe University)

$\begin{array}{cc}\text { Ashoka Prasad } & \begin{array}{c}\text { Psychiatrist (Victoria } \\ \text { (1988) }\end{array} \\ & \begin{array}{l}\text { Mental Health } \\ \text { Institute) }\end{array}\end{array}$

William McBride Director, Foundation (1988)
Nature of misconduct

Forged data on oral contraceptives challenged in 1981. Moves for inquiry blocked by legal injunction and university visitor. Second inquiry started in 1986, but Briggs resigned. ${ }^{\text {is }}$

Fifth book contained large scale plagiarism from 10 different sources. Resignation after difficulties with initial inquiry. ${ }^{16}$

Fabricated data on 1000 patients with schizophrenia, showing higher incidence of birth in winter. Committee of inquiry reported to state parliament. ${ }^{17}$

Forged data on studies of action of hyoscine on fetal rabbits. ${ }^{18}$

TABLE I-Knowledge of misconduct in medical publications among 79 respondents

\begin{tabular}{lcc}
\hline Discipline of respondents & No knowledge & Knowledge \\
\hline Medicine & 9 & 26 \\
Surgery & 17 & 10 \\
Editing & 6 & 8 \\
Other & 1 & 2 \\
\hline Total & 33 & $46 \dagger$ \\
\hline
\end{tabular}

*The non-respondent was a professor of surgery

†Representing 72 cases (including duplicates). Seven cases were mentione 18 times, giving total numbers of 61 distinct cases.

Fournal ${ }^{13}$ and the Vancouver recommendations for retracting published fraudulent work. ${ }^{1+}$

I also obtained details of a few cases in Australia, relying mainly on help from Dr Kathy King, editor of the Medical Fournal of Australia, as well as following up a few of the retractions, undisputed cases, and so on. ${ }^{15 \cdot 18}$

\section{Results and comment}

I approached 80 people, 79 of whom replied (table I). Over half of the correspondents knew of some instance of medical misconduct-most encountered firsthand, though a sizable minority were well authenticated secondhand instances - and there were a few rumours as well (tables II-V).

Most reports concerned episodes in Britain (41); episodes were also reported in the United States (seven), Australia (four), and other countries (seven). In 13 cases the country was not stated. A notable feature of the cases was a surprising proportion of senior workers (18 out of 43 cases in which the grade was given; table IV). Of the cases reported, more than half the results had been published, but only in six cases had subsequent retractions appeared, all in too vague terms to indicate the nature of the misconduct. Only three out of the 29 institutions reported mechanisms for investigating misconduct, though another respondent thought that if the possibility were raised some sort of ad hoc committee would be set up to deal with an individual case. The fate of the perpetrators was not always given (and to detail one or two of the cases would be to break promised confidentiality), but in some cases they were allowed to resign, a degree was disallowed, or there was ostracism by colleagues; not infrequently a researcher of intermediate grade had

moved to another department by the time of discovery and the new one disclaimed any responsibility. Only one perpetrator (not in this country) had been dismissed.

I have summarised four of the documented episodes in Australia (see main box). A notable feature was the way that in two cases appeals about the administrative details had been used to delay the process of inquiry. On the other hand, all of these cases had been brought into the open with official inquiries, and this had also happened eventually in another, non-medical, instance of plagiarism at the University of Newcastle, New South Wales."

\section{Discussion}

My small non-systematic survey found that misconduct in medical research certainly exists outside the United States but again provides no data on its prevalence. Nevertheless, most of these cases seem to be known to only a few people, little of the published work was retracted (and when it was so only in the vaguest of terms), and in Britain few institutions have any formal mechanism for dealing with instances of medical misconduct.

Clearly, the informality of the survey might be criticised. There were few ways of checking many of the statements, and yet they rang true for several reasons. Firstly, I knew most of the respondents (being able to address half of them by their Christian names); secondly, five of the cases were corroborated independently by other replies; and, thirdly, given the circumstances of the inquiry, the respondents had nothing to gain or lose from their replies.

\section{ARE THE NUMBERS UNDERESTIMATES?}

If anything, the results underestimate the true number of cases because total confidentiality was sometimes preserved: one respondent who had been concerned with a case as an examiner did not tell me about it (though he gave details of another case), but a friend of his (and mine) did; another respondent told me of a well authenticated case but said that he had been sworn to secrecy about the details (hence classified in table III under rumour). And sometimes in discussing the problem with outsiders I was told about yet other cases, which I added to the list if sufficient details were available. Finally, the survey did not cover other major disciplines, such as obstetrics and gynaecology or paediatrics, or subjects in which misconduct might be fairly common (such as clinical pharmacology), and I wrote to only one professor of surgery and medicine in each medical school, another feature which was liable to underestimate the true figures.

The pattern of misconduct resembles that of the

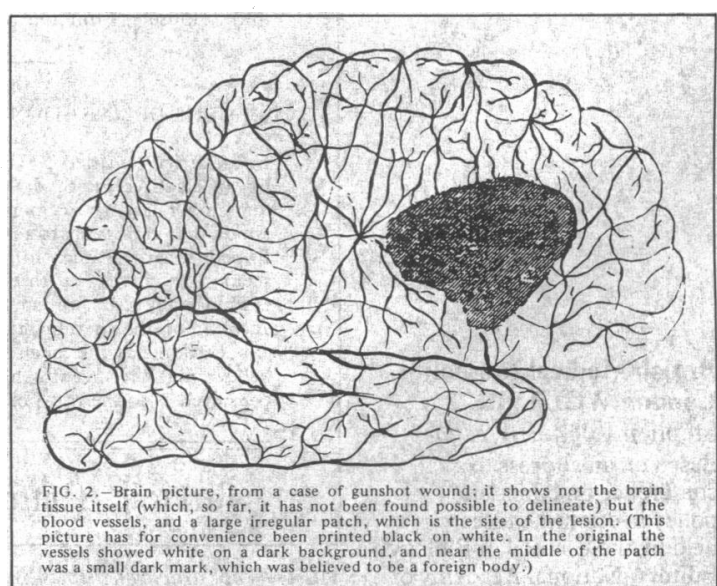

FIG 2-Figure from article on fames Shearer in " $B M \mathcal{F}$," 30 September 1916
Total No of cases $\begin{array}{llll}27 & 20 \quad 9 & 16\end{array}$

*Two respondents with knowledge of multiple cases were excluded. 


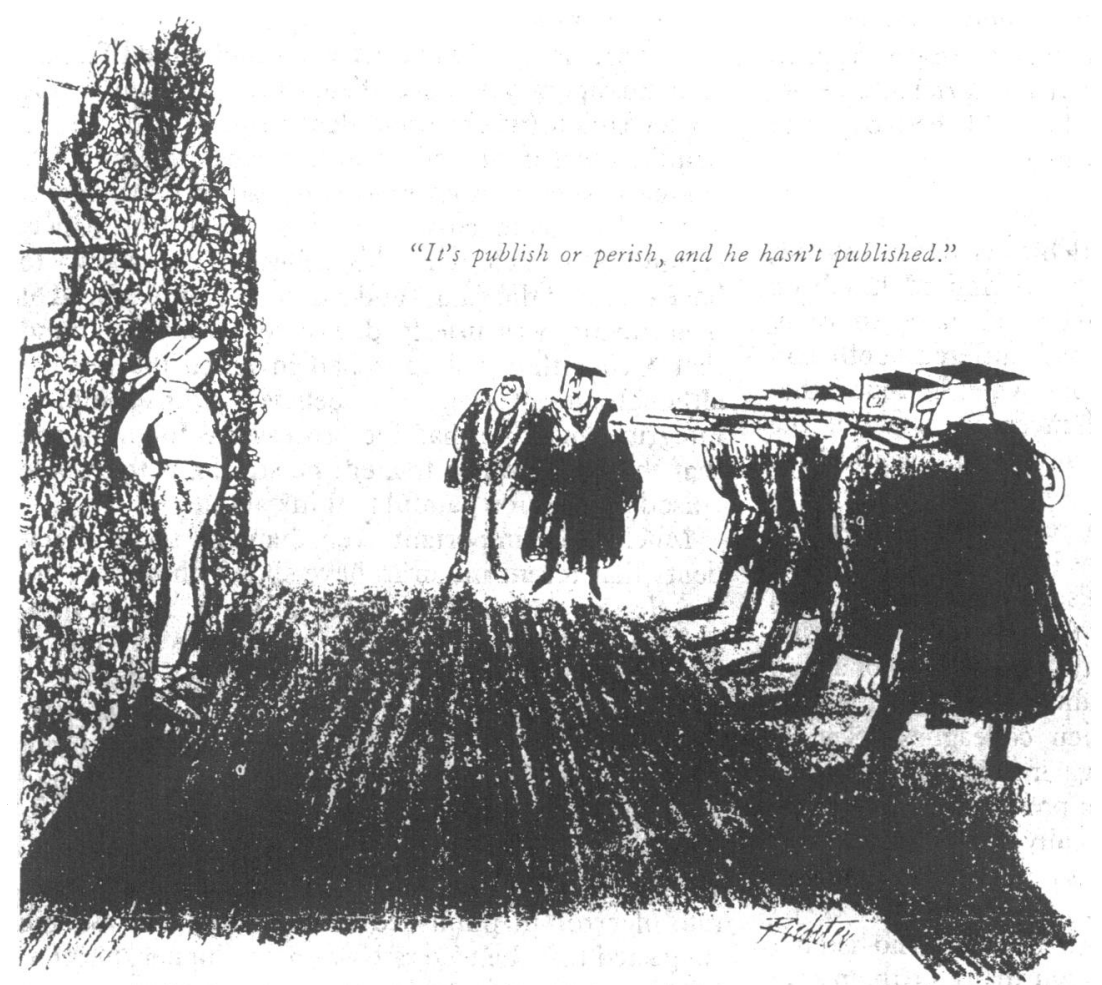

FIG 3-Drawing by Richter; copyright 1966, "The New Yorker" Magazine, Inc. Reproduced with permission studies had been "completed" before the drug was available for study.

Possibly this situation may change with the publication of a report by the Association of the British Pharmaceutical Industry on the relation between the medical profession and the drug industry..$^{20}$ This states that companies have a responsibility to ensure that all clinical trials are adequately monitored. If an investigator is suspected of deception or fraud this should be drawn to the attention of the association and through it, if necessary, to the General Medical Council or be dealt with by due legal process.

\section{OUTSIDE ACADEMIA}

The problems of setting up an inquiry outside an academic framework have been well illustrated in Australia with the recent allegations that William McBride, the physician who first described the teratogenic effects of thalidomide, had deliberately altered data from an inconclusive experiment on the actions of hyoscine on fetal rabbits. ${ }^{21}$ Carried out at Foundation 41 with two junior colleagues, who had been unaware of the changes, the work had been published in the Australian Fournal of Biological Research. Foundation 41 , of which $\mathrm{McBride}$ is chairman, is a private research organisation. In February 1988 scientists wrote to the Australian National Health and Medical Research Council urging an inquiry; the council said that it was willing to undertake it but only if formally asked..$^{22}$ In April 1988 the foundation asked the Australian Academy of Science to nominate a committee, but it is said to have declined, fearing litigation. ${ }^{23}$ In July 1988 the foundation set up its own committee, and in early November this reported that McBride had committed scientific fraud. ${ }^{18}$

As in Woolf's series the whistleblower in my series was usually a colleague at the same institution who had noted that the work had not been done or that no data were available or that a scientist elsewhere had failed to replicate the work.' Other mechanisms by which fraud was discovered were editorial peer review or a protest by the original author in cases of plagiarism. Hence, as Woolf emphasised, these cases show the effectiveness

TABLE III-Proximity of 72 cases of misconduct according to disciplines of respondent

\begin{tabular}{lccc}
\hline & Firsthand & $\begin{array}{c}\text { Authenticated } \\
\text { secondhand }\end{array}$ & Rumour \\
\hline Medicine & 20 & 16 & 3 \\
Surgery & 11 & 5 & 2 \\
Editing & 10 & 3 & \\
Others & & 2 & 5 \\
\hline Total & 41 & 26 &
\end{tabular}

TABLE IV-Discipline and grade of perpetrator in 72 cases of misconduct

\begin{tabular}{lrccc}
\hline & Senior & Intermediate & Junior & Not stated \\
\hline Medicine & 11 & 14 & & 7 \\
Surgery & 5 & 1 & & 4 \\
Other & 1 & 8 & 1 & 3 \\
Not stated & 1 & 23 & 2 & 29 \\
\hline Total & 18 &
\end{tabular}

Senior $=$ holding a consultant contract or equivalent; intermediate $=$ holding senior registrar, registrar, or lecturer contract or equivalent; junior= remainder.

TABLE $\mathrm{V}-$ Type of misconduct according to discipline of perpetrator

\begin{tabular}{lccc}
\hline & Plagiarism & Misrepresentation & Fraud \\
\hline Medicine & 1 & & 31 \\
Surgery & 2 & & 8 \\
Other & 2 & 2 & 3 \\
Not stated & 4 & 2 & 19 \\
\hline Total & 9 & 61 \\
\hline
\end{tabular}


in detecting misconduct of peer review in its broadest sense (at various stages of applying for a research grant, informal presentation of the work, editorial refereeing, and subsequent scrutiny of the published paper or attempted replication of the work).

\section{FATE OF WHISTLEBLOWERS}

Usually the fate of the whistleblower was not stated, but concern that they may be victimised has been raised in some reports from the United States. In two of my cases the whistleblower had suffered: both had found it necessary to resign, one when he found that his head of department had invented data but the circumstances were such that any inquiry would have been impossible.

I was surprised at the many respondents who knew of no cases at all, particularly as in a few instances their colleague at the same medical school told me of a well authenticated instance there. Apart from the trusting good nature of these respondents, this argues for a high degree of local confidentiality (in other words, they preferred not to tell their colleagues). Several respondents mentioned the legal implications of even a whisper of fraud, four of them preferring to telephone me with the details. Even if totally untrue such a taint might have serious implications for the future career of a research worker or clinician.

I was also surprised at the many editors who had not encountered misconduct, though many of them said that they had been "uneasy" about several articles (usually because the data seemed too good to be true); usually the implications of doing anything were too daunting in terms of time or legal hazards, and they had rejected the paper on general grounds. Perhaps the current dilemma was best put by the senior editor of a prestigious monthly journal: "Nearing the end of my time as editor the one thing I have really disliked is the prospect of receiving one article or letter a week containing data that I really don't believe."

On the other hand, at least one undoubted perpetrator was said to have brazened it out, threatening to sue his chief if he instituted disciplinary proceedings and retracted the published fraudulent work. His chief's resolve collapsed and nothing was done.

CONFUSION, HORROR OF PUBLICITY, AND SLOWNESS

In Britain all my findings echo those described in the United States by Angell, ${ }^{24}$ who commented that the initial responses to the early cases of fraud were marked by confusion and a horror of going public; action was also slow. Woolf has also suggested that, given that cases of misconduct (particularly plagiarism) are often handled locally, the total number is likely to be underestimated and that lawyers may often have an important role in preventing the disclosure of information and examination of the circumstances.' And not infrequently-particularly in the case of students detected who have invented or plagiarised data for a thesis-a bargain is struck: the thesis is disallowed and the student allowed to resign with nothing said publicly on the other side.

Medical misconduct must, of course, be viewed in perspective and not seen under every bed. In particular, we must be careful to allow full and careful discussions of data without any suggestion that these are fraudulent. I could not agree more with a recent correspondent in Nature who said that we must "decriminalise error." ${ }^{25}$ Most editors of major journals have received accusations, usually unsubstantiated and not infrequently implicating major workers. For that reason, remembering Majerus's dictum that "we are the $\mathcal{F C I}$, not the FBI,", ${ }^{26}$ the International Committee of Medical Journal Editors insisted that the onus of investigation should be on the institution where the work was done. ${ }^{14}$ The journal concerned then has the moral obligation to publish the findings.
STIGMA OF MISCONDUCT

Nevertheless, misconduct is an undoubted feature of contemporary science, being present even in the Soviet Union (where fraudulent results were used to damn a rival improved manufacturing process ${ }^{27}$ ). Its stigma is such that an innocent head of department, and a legitimate co-author of a fraudulent paper, committed suicide when his colleague was shown to have invented the data, ${ }^{28}$ and a friend of mine, a head of department, was utterly devastated when he found that a co-author colleague had invented the results; although at all stages he behaved with complete integrity, ensuring that due process was followed and that the article was retracted, he still finds the whole episode almost too painful to think about.

Much more important even than the serious incidents that recent inquiries have shown, however, are the sloppy standards of scientific work, authorship, and editing that have been disclosed. Thus an audit by the Food and Drug Administration showed serious deficiencies in the work of $11.5 \%$ of 964 investigations; 41 out of 42 workers disciplined by the Food and Drug Administration from June 1977 to February 1983 had engaged in scientific misconduct-economic fraud, false data, studies they were not qualified to conduct, and disregard of protocol. ${ }^{29}$ Instancing a $1 \%$ known rate of error in published biological papers, Sabine suggested that the true rate was much higher, particularly as some journals do not publish corrections as a matter of policy and, especially in fraud cases, decline to do so on legal grounds..$^{30}$

Authorship no longer carries the responsibilities it should - the ability to justify intellectually the entire contents of an article. ${ }^{31}$ The emergence of "big science" in medicine with large groups of research fellows means that there are not enough ideas to go round; the inevitable result is multiauthored papers, which are incompletely reviewed by all the authors, even if they are qualified to have their names on the article. ${ }^{32}$

\section{"GIFT" AUTHORSHIP}

Often, however, authorship is non-legitimate, granted as a gift (as in the Slutsky case). I wish I could remember who it was who commented on the absurdity of such co-authorship by saying that it's a bit like claiming you wrote Hamlet because you lent Shakespeare a pencil. But the same is happening in Britain; a colleague of mine, hypnotised by the new Grateful Med program at the National Library of Medicine, Bethesda, idly tapped in the names of two British workers. ${ }^{33}$ Nobody could accuse either of fraud, but they had certainly published too many papers bearing their names -in three years one had almost 200 papers bearing his name, the other almost 100. I find these figures, and the ethos they represent, absurd; nobody can possibly take responsibility for this number of articles.

Finally, the committee of inquiry into the Slutsky episode was surprised at the extent to which the co-authors had passively accepted the events. ${ }^{13}$ None had written to the journals asking for the articles to be retracted, and none had showed any interest in repeating the experiments or the calculations. The response of the journal editors was equally disappointing. Some said that they did not publish retractions, others that they did so only if all the co-authors agreed, and yet others did not answer letters making official requests to do so.

\section{ACTION NEEDED IN BRITAIN}

Given all this, the next stop should be for the British authorities to recognise the situation and resolve to tackle it. So far as sloppy science is concerned the solution must be with the individual institutions- 
particularly the heads of departments - in tackling the problems of gift authorship, salami publication, and duplicate publication. Editors can help, but the prime responsibility for standards is that of the institution.

For plagiarism and fraud concerted official action is needed. One way would be for the official bodies (including the General Medical Council, Association of the British Pharmaceutical Industry, Medical Research Council, and the medical royal colleges) to get together and follow American practice, devising some uniform, fair mechanism whereby each institution could bring any suspected or proved case into the daylight and deal with it fully and fairly. The pattern of a university academic offences committee, with its procedures following the format expected in a court of law, might be a good starting point for this. Another possibility is to copy the FDA's black list of clinical investigators. And research bodies in Britain might consider following the example of the National Institutes of Health, ${ }^{34}$ by insisting that a prerequisite for a research grant is that the institution possesses a mechanism for investigating fraud.

This said, however, the problems of medical misconduct occurring outside academic institutions also need consideration. I believe that what is wanted are greatly strengthened local ethics committees, probably with legal representatives. These committees would also need some sort of audit of their performance to ensure that standards were uniform and were maintained. For lesser cases, caught between the possibility of a full scale Slutsky type inquiry and doing nothing, the authorities might consider the case for establishing a confidential advisory service, on the lines, say, of those provided for those worried about drunk or delinquent colleagues. This might provide advice for whistleblowers, heads of departments, and even the perpetrators caught up in cases of misconduct.

Whatever the answers, Britain should be reassured by the experience in America, where within the past decade most of the entire process has been worked through. Firstly, a form of scientific deviance was identified; secondly, it was studied; thirdly, steps were taken to deal with existing cases and to try to prevent new ones. The final stage - which I hope is in progress - is some sort of audit to see whether all these measures have diminished a small but serious blot on the face of medical research.

\section{WHY DO ANYTHING?}

Some might question these suggestions. Why do anything? After all, it might be argued, some sort of action is taken eventually in most overt cases of fraud even if this is only neglect of the data or ostracism of an identified wrongdoer by the invisible college. Nevertheless, there are several reasons for what the Americans would call an active stance of due process. Firstly, fraud is a crime. As Medawar commented, "I do not find this crime bewildering and inexplicable; it strikes me as a straightforward felony of which scientists must be supposed no less capable than other professional men." Secondly, too many such felonies have gone unprevented, uninvestigated, or undetected, and this will encourage others into attempting themwith a consequent unethical waste of people, materials, money, and time in both the laboratory and the journal office. And, finally, if medicine and science no longer carry the hallmark of a profession - self correctionthen official outside agencies are likely to do the correcting for them, and proposals have already arisen in the United States to establish a central "Office of Scientific Integrity" and to make gift authorship a crime. ${ }^{33}$

Australia seems to have tackled the problem better than Britain, given the few cases reported in each country. Firstly, the problem has been brought into the open and, secondly, eventually the authorities have recognised that properly constituted inquiries are needed to allay professional and public alarm. We in Britain should follow their example.

I thank Professor J C E Underwood and Dr T Healey for details of the Shearer case; Mr W Murphy for drawing my attention to the New Yorker cartoon; Dr Patricia Woolf and Janie Smith for many illuminating discussions; and the many respondents for their prompt and helpful replies.

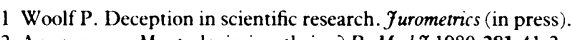

2. Anonymous. Must plagiarism thrive? Br Med f 1980;281:41-2.

3 Anonymous. In Bristol now. Nature 1981;294:509.

4 Anonymous. Differential diagnosis of dementia. Br Med f 1987;294:1236.

Medawar PB. Advice to a young scientist. Cambridge: Harper and Row, 1979.

6 Anonymous. GMC professional conduct committee. Br Med f 1988;296:306.

Anonymous. The delineation of internal organs by an electrical method. BrMed F 1916;ii:459-61.

8 Anonymous. The delineation of internal organs. BrMed F 1917;i:401

9 Mould RF. A history of $x$-rays and radium. Sutton: IPC, 1980:42.

10 Koshland DE. Fraud in science. Science 1987;235:141.

11 Broad W, Wade N. Betrayers of the truth. New York: Simon and Schuster, 1982.

12 Lock S. Fraud in medicine. $\mathrm{Br}$ Med $\mathrm{f}$ 1988;296:376-7.

13 Engler RL, Covell JW, Friedman PJ, Kitcher PS, Peters RM. Misrepresentation and responsibility in medical research. New Engl 7 Med 1987;317 1583-9.

14 International Committee of Medical Journal Editors. Guidelines on authorship. Br Med f 1985;291:722.

15 Smith D. Renewed attack on pill researcher. The National Times 25-31 July 1986:22.

6 McAdam A. Professor resigns after barrage of plagiarism charges. The Bulletin 1 July $1986: 30$.

17 Conley J. Researcher's qualification and data false, says report. The Age 31 March 1988.

18 Swan N. Science: not always right but it can't be wrong. Sydney Morning Herald, 3 November 1988.

19 Duncan T. Unit standards threatened by PhD student scandal. The Bulletin 25 September 1986:26-9.

20 Association of the British Pharmaceutical Industry. Relationship between the medical profession and the drug industry. London: ABPI, 1987.

21 O'Neill G. Fraud claim on Debendox campaigner. The Age 14 December 1987.

21 O'Neill G. Fraud claim on Debendox campaigner. The Age 14 December 1987.
22 Lagan B. Public inquiry urged into allegations against McBride. Sydney Morning Herald 2 February 1988.

23 Ewing T. Australian scientists differ on how to attack fraud. Nature 1988;332:671

24 Angell M. Fraud in science. Science 1983;219:1418-9.

25 Petsko GA. Unreproducible results. Nature 1988;335:109.

26 Majerus P. Fraud in medical research. F Clin Invest 1982;70:213-7.

27 Richman V. Falsified data help to keep Soviet metal pockets lined. Nature 1986;326:634.

28 Palca J. Investigations into NIH fraud allegations end with suicide. Nature 1987;325:652.

29 Shapiro MF, Charrow RP. Scientific misconduct in investigational drug trials. New Engl J Med 1985;312:731-6.

30 Sabine JR. The error rate in biological publication. Science, Technology, and Human Values 1985;10:62-9.

31 Huth EJ. How to publish papers in the medical sciences. Philadelphia: ISI Press,

1982 .
32 Petersdorf RG. The pathogenesis of fraud in medical science. Ann Intern Med 1986;104:252-4.

33 Lock S. Scientific misconduct-again. Br Med $\mathcal{F}$ 1988;297: 1079-80.

34 Angell M, Relman AS. Fraud in biomedical research. New Engl $\mathcal{f}$ Med 1988;318:1462-3.

\section{ANY QUESTIONS}

Is there any evidence that commonly used sugar substitutes such as saccharin and aspartame are carcinogenic in normal usage?

There is no evidence that either saccharin or aspartame are carcinogenic in normal usage. The more recently introduced substitutes such as aspartame have been through an exhaustive series of toxicological studies and no carcinogenic effects were observed. The recent debate about aspartame centres on possible effects on mood and behaviour from its amino acid components. In the case of saccharin studies in rats showed an association with bladder cancers. These were at high levels of usage and a detailed examination of the incidence of bladder cancer in humans, especially diabetics with a high use of sugar substitutes, has shown no increased risk associated with the use of sweeteners. ${ }^{12}-$ D A T soUTHGATE, head, nutrition and food quality research, AFRC Food Research Institute, Norwich.

1 Armstrong B, Doll R. Bladder cancer mortality in England and Wales in relation to cigarette smoking and saccharin consumption. British relation to cigarette smoking and saccharin consumption.
foumal of Preventive and Social Medicine 1974;28:233-40.

2 Kessler II, Clark JP. Saccharin, cyclamate and human bladder cancer. No evidence of an association. JAMA 1978;240:349-55. 